\title{
The Role of Hba1c in Severity and Mortality Rate of St Segment Elevation Myocardial Infarction for Hospitalized Libyan Non Diabetic Patients
}

\author{
Hanan K. G. Altalhi ${ }^{*}$, Asgad A. Abdalgbar ${ }^{12}$ \\ ${ }^{I}$ Faculty of Medicine, University of Omar El mukhtar, Albayda, Libya \\ ${ }^{2}$ Faculty of Medical Technology, University of Omar El Mukhtar, Albayda, Libya
}

*Corresponding Author: Hanan K. G. Altalhi, Faculty of Medicine, University of Omar El mukhtar, Albayda, Libya, Email: hnangk@yahoo.com

\begin{abstract}
:
Background: The severity of coronary artery disease (CAD) is directly related to the quality of glucose control in diabetic patient. Additionally diabetes is associated with increased mortality following acute myocardial infarction compared to general population.
\end{abstract}

Objectives: To evaluate the association of HbAlc level and severity of $C A D$, and outcome of non diabetic patient with STEMI In our hospital.

Patients and methods: 60 consecutive non diabetic patient with acute ST elevation myocardial infarction were treated with thrombolytic therapy included in the present prospective study. Blood glucose and HbAlc level of all patients were measured within 3 hours of admission. Patient were divided in to 3 groups according to HbAlc level: with cut-off $6.5 \%$ as diagnostic criteria of diabetes mellitus according to (American diabetes association) group (1) $6.5 \%$, group (2) 6.5 to $8.5 \%$, group (3) $8.5 \%$ and above.

In hospital. mortality and morbidities of acute STEMI were compared between groups.

Result: The mean age was $63 \pm 15$ year and mean body mass index was $26.6 \pm 6 \mathrm{~kg} / \mathrm{m}^{2}$, 24 patients (40\%) had history of hypertension, 27 patients (45\%) of dyslipidemia, 36 patients (60\%) were smoker.

We found 45 patients with $\mathrm{HbAlc} \leq 65 \%$, 5 patients with HbAlc $6.5-8.5 \%$, 10 patients with HbAlc $\geq 8.5 \%$.

There was strong correlation between admission of HbAlc and admission glucose level (P<0.001). Infarct size as measured by peak creatinin kinase, was not correlated with HbAlc level.

Conclusion: HbAlc is an important risk marker in the absence of history of diabetes mellitus in patients with AMI. The optimal management in these patients may contribute in decrease hospital mortality.

Keywords: Glycosylated Hemoglobin (HbAlc); ST elevation myocardial infarction (STEMI) mortalities, Diabetes

\section{INTRODUCTION}

Patients with diabetes are at 3-4 times increased risk for cardiovascular mortality compared with nondiabetes (Preis PR etal. 2009). In acute coronary syndrome, glucose metabolism is modified and stress hyperglycemia commonly occur secondary to increase catecholamine level (Husband DJ etal. 1983). In addition to the higher rate of acute ST- elevation myocardial infarction (STEMI) in diabetes, hyperglycemia is associated with poor prognosis in these patients (Wahab N et al. 2002; Wiviott $\mathrm{S}$ et al.2008; Li D et al 2011).

Higher HbAlc level was associated with high cardiovascular disease and death (Selvin E et al.
2010). There were some other studies supporting the association between admission serum $\mathrm{HbA1c}$ level and increased long-term mortality of non diabetic patients admitted with STEMI and higher rate CAD in these patients (Timmer J et al 2011, Pia J et al 2013). We have evaluated the association of admission level of $\mathrm{HbA1c}$ with the hospital outcome of non diabetic patient with STEMI.

\section{Patients And Methods}

All patients of both sexes sustaining acute ST elevation myocardial infarction without diabetes were including in the study. Patients with sepsis, hemoglobinopathies or hypothyroidism tumor, 
connective tissue diseases, those with sub-acute or chronic MI (longer than $48 \mathrm{hr}$ between first symptom and admission) those with renal failure, hepatic failure, iron deficiency anemia and those with past history of diabetes or used anti diabetic medication were excluded from the study.

Acute myocardial infarction was defined according to the (European Society of Cardiology and American College of Cardiology Criteria).

Increased creatine kinase predominantly in the myocardial band fraction and or increased troponin I (creatine kinase $400 \mathrm{U} / \mathrm{L}$ or higher and or cardiac troponin I $2 \mu \mathrm{g} / \mathrm{L}$ or higher), ischemic symptoms (mainly constrictive chest pain, lasting longer than $30 \mathrm{~min}$ ), and or abnormal electrocardiography (ST elevation 1 $\mathrm{mm}$ or greater on at least two derivation). MI was defined as acute if the time elapsed between the first symptom and admission was $48 \mathrm{hr}$ or less. only patients who underwent thrombolytic treatment were included in the study.

All patients were in cardiac care unit, a brief history was obtained from each patient presenting with acute chest pain including presence of risk factors like smoking and hypertension, dyslipidemia and previous history of ischemic heart disease. Clinical examination was done emphasis on signs of cardiac failure, 12 leads electrocardiography (ECG) was done at cardiac care unit and blood sample were sent to laboratory, blood glucose and $\mathrm{HbA} 1 \mathrm{c}$ level of all patients were measured within $3 \mathrm{hr}$ of admission regardless of whether they had been fasting or not and for cardiac enzyme. The fasting lipid profile was determined on the morning following admission and included total cholesterol, high density lipoprotein and triglyceride.

All patients were considered for thrombolytic therapy (Injection streptokinase 1.5 million units over one hour) in the absence of all contraindication the management was according to standard treatment protocol. All patients underwent continues ECG monitoring for at least 48 hours on admission to cardiac care unit and daily during hospital stay.

Patients were divided into three groups according to the level of $\mathrm{HbA} 1 \mathrm{c}$ with cut-off $6.5 \%$ as diagnostic criteria of diabetes mellitus according to (American Diabetes Association 2010) for diagnosis and classification of diabetes mellitus. Patient with $\mathrm{HbA} 1 \mathrm{c}$ level of $4.5 \%$ to $6.4 \%$ group (1), patients with HbA1c level $6.5 \%$ to $8.5 \%$ group (2) and patients with $\mathrm{HbA1c}$ level higher than $8.5 \%$ group 3 ).

None of these patients received glucose, Insulin or potassium infusion therapy during admission. All subjects were hospitalized one week after acute myocardial infarction and hospital records were reviewed at this time.

Selective coronary angiography was performed after 1 month. Coronary angiogram was analyzed by two experienced observers who were blinded to the identities and clinical information of the patients. Vessel scores were ranged from zero to three, according to the number of diseased major pericardial vessel with significant stenosis (greater than 50\% stenos is of the lumen diameter).

Statistical Analysis: Was performed by using SPSS software (Version 12) difference among groups was analyzed by (t-test) and $\mathrm{P}$ value 0.05 was considerable significant.

\section{RESULT}

Total 60 patients with STEMT were studied. Patients were divided on the bases of admission HbA1c group (1) $\leq 6.5 \%$; group (2) 6.5-8.5 \%; group $3 \geq 8.5 \%$.

The clinical and biological characteristic according to HbA1c are summarized in (table1). The mean age was $63 \pm 15$ year and mean body mass index was $26.6 \pm 6 \mathrm{~kg} / \mathrm{m}^{2}, 24(40 \%)$ had history of hypertension, 27 (45\%) of dyslipidemia, $36(60 \%)$ were smoker. We found 45 with $\mathrm{HbAlc} \leq 6.5 \%$; 5 with HbA1c 6.5 $8.5 \%, 10$ with $\mathrm{HbA} 1 \mathrm{c} \geq 8.5 \%$.

There was strong correlation between admission $\mathrm{HbAlc}$ and admission glucose level $(\mathrm{P}<$ $0.0001)$. Infarct size as measured by peak creatinin kinase, was not correlated with HbAlc level.

Table1. Clinical and biological characteristics of the study subjects. According to admission HbA1c level

\begin{tabular}{|l|l|l|l|l|l|}
\hline \multicolumn{5}{|c|}{ Level of Glycated Hemoglobin } \\
\hline & All $\mathrm{n}=60$ & Group1 <6.5\% n=45 & Group2 6.5-8.5\% N=5 & Group3>8.5N=10 & P Value \\
\hline Age(year) & $63 \pm 15$ & $61 \pm 15$ & $60 \pm 17$ & $70 \pm 10$ & 0.02 \\
\hline Sex(M/F)n & $48 / 12$ & $40 / 5$ & $3 / 2$ & $7 / 3$ & 0.4 \\
\hline $\begin{array}{l}\text { Current or former smoker } \\
\%\end{array}$ & $36(60)$ & $29(65)$ & $2(40)$ & $6(60)$ & \\
\hline
\end{tabular}


The Role of Hba1c in Severity and Mortality Rate of St Segment Elevation Myocardial Infarction for Hospitalized Libyan Non Diabetic Patients

\begin{tabular}{|c|c|c|c|c|c|}
\hline $\mathrm{BMI}\left(\mathrm{kg} / \mathrm{m}^{2}\right)$ & $26.6 \pm 6$ & $26.1 \pm 5$ & $26.7 \pm 4.2$ & $29 \pm 4.9$ & 0.05 \\
\hline Admission SBP(mmHg) & $132 \pm 25$ & $129 \pm 25$ & $136 \pm 22$ & $143 \pm 25$ & 0.05 \\
\hline Admission DBP $(\mathrm{mmHg})$ & $72 \pm 18$ & $72 \pm 15$ & $71 \pm 14$ & $76 \pm 23$ & 0.05 \\
\hline $\begin{array}{l}\begin{array}{l}\text { Admission plasma } \\
\text { glucose }(\mathrm{mmol} / \mathrm{L})\end{array} \\
\end{array}$ & $8.2 \pm 3.7$ & $7.7 \pm 2.9$ & $8.2 \pm 2.2$ & $11.2 \pm 6.5$ & $<0.0001$ \\
\hline Totalcholesterol $(\mathrm{mmol} / \mathrm{L})$ & $6 \pm 1.2$ & $6.1 \pm 1.3$ & $6.3 \pm 0.9$ & $5.5 \pm 1.1$ & 0.01 \\
\hline HDLcholesterol(mmol/L) & $1 \pm 0.4$ & $1.3 \pm 0.4$ & $1.2 \pm 0.1$ & $1.2 \pm 0.3$ & 0.27 \\
\hline Triglyceride(mmol/L) & $1.53 \pm 0.89$ & $1.47 \pm 0.86$ & $1.88 \pm 0.89$ & $1.56 \pm 0.99$ & 0.36 \\
\hline $\begin{array}{l}\text { Peak CK in first } 24 \\
\text { hour(U/L }\end{array}$ & \begin{tabular}{|l|}
903 \\
$(210-3256)$
\end{tabular} & $\begin{array}{l}1979 \\
(580-3227)\end{array}$ & $\begin{array}{l}1500 \\
(647-3000)\end{array}$ & $\begin{array}{l}1486 \\
(504-3126)\end{array}$ & $\mathrm{NS}$ \\
\hline
\end{tabular}

Data are mean $\pm S D, B M I$, body mass index ie body weight $(\mathrm{kg}) / \mathrm{hight}^{2}\left(\mathrm{~m}^{2}\right)$. SBP/ DBP, systolic / diastolic blood pressure; $C K$ Creatin in kinase

Patients were divided according to admission glucose [group (1), $6.9 \mathrm{mmol} / \mathrm{L}$; group (2), 7 to $8.1 \mathrm{mmol} / \mathrm{L}$; group (3), 8.2 to $9.5 \mathrm{mmol} / \mathrm{L}$; group (4) $\geq 9.6 \mathrm{mmol} / \mathrm{L}]$.

There was significant positive correlation between admission glucose and infarct size measured by peak creatinin kinase level $(\mathrm{P}<0.0001)$.

Table2. Clinical outcome of non diabetic patients based on quantities of admission plasma glucose

\begin{tabular}{|c|c|c|c|c|c|}
\hline \multicolumn{6}{|c|}{ Admission Glucose Level } \\
\hline & IQR1 $6.9 \mathrm{mmol} /$ & IQR2 7-8.1mmol/L & $\begin{array}{c}\text { IQR3 } \\
\text { 8.29.5mmol/L }\end{array}$ & IQR4 $\geq 9.6 \mathrm{mmol} / \mathrm{L}$ & $P$ value \\
\hline $\begin{array}{l}\text { Infarct size } \\
\text { Peak.CK in the } \\
\text { first } 24 \mathrm{hr}\end{array}$ & $530(210-1150)$ & $903(327-2050)$ & $1367(564-2924)$ & $1912(827-3256)$ & $<0.0001$ \\
\hline
\end{tabular}

$I Q R=$ inter quartile range; $C K=$ cratin in kinase. Value are expressed as median $(I Q R)$

At the end of fourth week coronary angiography performed in remaining 54 patients, revealed HbA1c level at admission and number of that there was significant correlation between

Table3. Angiographic data of patients according to HbAlc

\begin{tabular}{|c|c|c|c|c|}
\hline \multicolumn{5}{|c|}{ Level of Glycosylated Hemoglobin } \\
\hline $\begin{array}{c}\text { Number of diseased } \\
\text { vessel } \mathbf{N}(\%)\end{array}$ & $\begin{array}{c}\text { Group1 }<6.5 \% \\
N=39\end{array}$ & $\begin{array}{c}\text { Group2 6.5\%-8.5\% } \\
N=5\end{array}$ & $\begin{array}{c}\text { Group3 }>8.58 .5 \% \\
N=10\end{array}$ & P Value \\
\hline Single vessel & $30(76.9 \%)$ & $3(60 \%)$ & $1(10 \%)$ & 0.000 \\
\hline Double vessel & $7(17.9 \%)$ & $1(20 \%)$ & $4(40 \%)$ & 0.16 \\
\hline Triple vessel & $2(5.1 \%)$ & $1(20 \%)$ & $5(50 \%)$ & 0.001 \\
\hline
\end{tabular}

We found that patients who died by day 5 were significantly different from patients with non-lethal acute myocardial infarction, with regard to admission plasma glucose (16.6 \pm 5.4 vs $8.3 \pm 3.4 \mathrm{mmol} / \mathrm{L}, \mathrm{P}=0.0001)$, age ( $74 \pm 10$ vs $62 \pm 13$ year, $\mathrm{P}=0.002$ )

Table4.Clinical characteristics of patients according to the mortality at 5 days after acute myocardial infarction

\begin{tabular}{|l|l|l|l|}
\hline & Dead by day 5 N=6 & Alive by day 5 N=54 & P Value \\
\hline Age $($ year) & $74 \pm 10$ & $62 \pm 13$ & 0.002 \\
\hline Sex (M/F) & $6 / 0$ & $42 / 12$ & 0.33 \\
\hline Peak creatinin kinase (IU/L) & $1068(1120-3256)$ & $825(210-1860)$ & 0.02 \\
\hline Admission plasma glucose (mmol/L) & $16.6 \pm 5.4$ & $8.3 \pm 3.4$ & 0.0001 \\
\hline HbA1c & $6.7 \pm 1.8$ & $6.2 \pm 0.2$ & 0.15 \\
\hline
\end{tabular}

HbAlc $=$ Glycosylated hemoglobin

\section{DISCUSSION}

The present study confirms previous observation in diabetic subjects suggesting that higher glucose level during AMI are associated with increased mortality (Sewaradsen M, et al 1989). In recent study, (Timmer J, et al 2011) reported
There was no significant difference in HbA1c value in the survivor and non-survivor $(6.7 \pm 1.8$ vs $6 \pm 0.2, P=0.15)$. that higher admission glucose level in non diabetic patients treated with reperfusion therapy for ST segment elevation MI were associated with significantly larger enzymatic infarction size and lower left ventricular ejection fraction. This is because a stress response is 
accompanied by high level of catecholamine and cortisol and these hormones increase glucogenolysis and lipolysis and reduce insulin sensitivity, resulting in elevated glucose level (Seaquist ER, et al 2013) There for, patients with elevated glucose level may represent with an increased stress response, due to more sever hemodynamic compromise or more extensive myocardial damage (Gosselink AT., et al 1998; DeGeare VS, et al 2001). Elevated cytokine, particularly tumor necrosis Factor-Alpha (TNF$\alpha$ ), also increase glucose level. TNF- $\alpha$ is released in AMI and directly decrease myocardial contractility, probably by inducing myocardial apoptosis (Li D, et al 1999; Li YP et al 2001). TNF $-\alpha$ also cause impaired endothelial function (Fujita H, et al 1999). This in turn, may be responsible for the impaired myocardial perfusion. We found positive correlation between peak creatinin kinase and admission plasma glucose concentration in our patients. Conversely, no correlation was found with HbA1c value. Although acute hyperglycemia at admission and during stay has clearly been associated with adverse outcome in patients with acute MI (Capes E, et al 2000; Norhmmar A, et al 2002; Timmer J, et al 2004).

Our study shows admission HbA1c level are not associated with high mortality in non diabetic STEMI population treated with streptokinase. In our study high $\mathrm{HbA1c}$ in non diabetic patients associated with multivessele involvement of coronary arteries. Similarly, (CakMak, et al 2008) reported a significant correlation between $\mathrm{HbA} 1 \mathrm{c}$ level at admission and positive exercise that result after the four week follow up.

Hyperglycemia in STEMI patients was strongly associated with increased mortality within 5 days although there is clear correlation between admission glucose and HbA1c level, they appear to represent related but different phenomena. Patients with elevated glucose level have larger MI area.

Recently a prospective cohort study showed that in non diabetic general population, as elevated $\mathrm{HbA} 1 \mathrm{c}$ level is a risk factor for the development of cardiovascular events independently of fasting glucose (Selvin E, et al 2009). The international expert committee recommended the use of HbA1c in diagnosis diabetes with a cut-off $6.5 \%$ (Gillet M, et al. 2009).

The advantage of HbA1c over the fast blood glucose are its lower intra-individual variability, assessment in non fasting state and superior in monitoring blood glucose level (Selvin et al .2007; American Diabetes Association, 2009). (Preis et al .2009 Selvin et al 2010) has suggested that glycosylated hemoglobin is superior to fasting blood glucose in predicting long-term risk of CAD in non diabetes. Similar result are reported by Park and colleagues among non diabetic women (Park et al. 1996). In a cohort of European men, khaw and colleagues reported that $\mathrm{HbA1c}$ correlates linearly to subsequent cardiovascular morbidity, (Khaw et al 2001). The American Diabetes Association suggests that individual with HbAlc concentration of 5.7- $6.4 \%$ should be informed of their increased risk for diabetes as well as cardiovascular disease (American Diabetes Association 2010).

\section{CONClusion}

$\mathrm{HbA1c}$ is an important risk marker in the absence of history of diabetes mellitus in patients with AMI. The optimal management in these patients may contribute in decrease hospital mortality. People at high risk for type II diabetes mellitus should receive lifestyle counseling and if needed pharmacological therapy to reduce their risk of developing hyperglycemia and type II diabetes mellitus but especially to prevent or slow the development of CAD.

\section{REFERENCES}

[1] American Diabetes Association Diagnosis and classification of diabetes mellitus. Diabetes care 2010; 33 Suppl 1: S62 - S69. Doi: 10 .2337/dc 10-S062]

[2] Ashra f H, Boroumand MA, Amirzadegan A, Talesh SA, Davoodi G. Hemoglobin A1C in non diabetic patients; an independent predictor of coronary artery disease and its severity. Diabetes Res Clin Pract. 2013; 102: 225-232. Doi 10.1016/j. diabres .2013. 10. 011.

[3] Cakmak, M., Cakmak, N., Cetemen, S., Tanrverdi,, H., Enc, Y., Teskin, O. et al. (2008 The value of admission glycosylated hemoglobin level in patients with acute myocardial infarction. Can J Cardioln24:375378.

[4] Capes S, Hunt D,Malmberg K,Gerstein H. Stress hyperglycemia and the risk of death after myocardial infarction in patients with and without diabetes : a systematic overview. Lancet 2000: 355:773-778

[5] DeGeare VS, Boura JA, Grines LL, O Neill WW, Grines CL. Predective value of the Killip classification in patients undergoing primary precutaneous coronary intervension for acute 
myocardial infarction Am J Cardiol. 2001; 87: 1035-8.

[6] Daibetes Control and complication Trial (1996) The absence of a glycemic threshold for the development of long term complications the perspective of the Diabetes Control and Complications trial. Diabetes 45:1289-1298.

[7] Fujita H, Morita I, Murota S. A possible involvement of in transporter in tumor necrosis factor alpha and cycloheximide-induced a apoptosis of endothelial cells. Mediators Inflamm. 1999; 8: 211-8.

[8] Gerrity R., Natarajan R., Nadler J., Kimsey,T. (2001) diabetes induced accelerated atherosclerosis in swine. Diabetes 50: 1654 1665

[9] Ghaffari S., Nadiri M., Pourafkari L., Sepehrvand N., Movasagpoor A., Rahmatvand N., (2014) The predictive value of total neutrophil count and neutrophil/lymphocyte ratio in predicting in- hospital mortality and complications after STEMI. J Cardiovascular Thorac Res 6:35-41.

[10] Gillett M. (2009) International Expert Committee Report on the role of the HA1c assay in the diagnosis of diabetes: Diabetes Care 2009;1327-1334. Clin Biochem Rev 6: 197-200.

[11] Gosselink AT, Liem AL, Reiffers S, Zijlstra F. Prognostic value of predischarge radionuclide venrticulography at rest and exercise after acute myocardial infarction treated with thrombolytic therapy or primary coronary angioplasty. The Zwolle Myocardial Infarction Study Group. Clin Cardiol. 1998; 21: 254 - 60.

[12] Husband DJ, Alberti KG, Julian DG. Stress hyperglycemia during acute myocardial infarction: an indicator of pr-existing diabetes Lancet 1983, ii:179-181.

[13] S. E. Kassaian. H. Goodarznejad, M. A. Boroumand et al., Glycosylated hemoglobin (HbA1c) level and clinical outcomes in diabetic patients following coronary artery stenting, Cardiovascular Diabetology, vol. 11, article $82,2012$.

[14] Khaw K., Wareham N., Luben R., Bingham S., Oakes S., Welch A., (2001) Glycated haemoglobine, diabetes and mortality in men in Norfolk cohort of European peospective investigation of Cancer and Nutrition (EPICNorfolk). BMJ 322: 15-18.

[15] Li D, Zhao L, Liu M, et al. Kinetics of tumor necrosis factor alpha in plasma and the cardioprotective effect of monoclonal antibody to tumor necrosis factor alpha in acute myocardial infarction. Am heart J. 1999; 137: 1145-52.].
[16] Li YP, Reid MB. Effect of tum or necrosis factor-alpha on skeletal muscle metabolism. Curr Opin Rheumatol. 2001; 13:483-7]

[17] Norhammar A, tenerz A, Nilsson G, Efendic S, Ryden I., Malmberg K. Glucose metabolism in patients with myocardial infarction and no previous diagnosis of diabetes mellitus; a prospective study. Lancet 2002; 359:21402144.

[18] Pai, J., Cahill, L., Hu, F., Rexorde, K., Manson, J. and Rimm, E. (2013) hemoglobin A1c is associated with increased risk of incident coronary heart disease among apparently healthy, non diabetic men and women J Am Heart Assoc 2: e000077.

[19] Park, S., Barrett-Connor, E., Wingard, D., Shan, J. and Edelstein, S. (1996) GHB is better predictor of cardiovascular disease than fasting or post challenge plasma glucose in women without diabetes. The Rancho bernardo Study. Diabetes Care 19: 450-456.

[20] Preis, S., Hwang, S., Coady, S., Pencina, M., D Agostino, R., Sr., Savage, P. et al. (2009) Trends in all-cause and cardiovascular disease mortality among women and men with and without diabetes mellitus in the -Framingham Heart study, 1950 to 2005. Circulation 119: 1728-1735.

[21] Seaquist ER, Anderson J, Childs B, Cryer P, Dagogo-Jack S, Fish L, Heller SR, Rodrigues H Rosenzweig J, Vigersky R. Hyopglycemia and diabetes: a report of a workgroup of the American Diabetes Association and Endocrine Society. Diabetes Care. 2013; 36:1384-1395. Doi $10.2337 / \mathrm{dc} 12-2480$. [PMC free article] [PubMed] [Cross Ref].

[22] Selvin, E., Streffes, M., Zhu, H., Matsushita, K., Wagenknecht, L., Pankow, J. et al. 92010) Glycated hemoglobin, diabetes, and card iovascular risk in non diabetic adults. $\mathrm{N}$ Engl J Med 362: 800-811

[23] Sewardsen M, Vythilingum S, Jailal I, Becker PJ. Prognostic importance of admission plasma glucose in diabetic and non diabetic patients with acute myocardial infarction. Q J Med 1989; 265:461-6

[24] The Joint European Society of Cardiology/American college of cardiology Committee for the Redefinition of myocardial infarction. Myocardial infarction redefined-a consensus document. Eur Heart J 2000; 21: 1502-13.

[25] Timmer, J., Hoekstra, M., Nijsten, M., Van Der Horest, I., Ottervanger, J., Slingerland, R. et al. (2011) Prognostic value of admission glycosylated hemoglobin and glucose in non diabetic patients with ST-segment-elevation myocardial infarction treated with percutaneous 
The Role of Hba1c in Severity and Mortality Rate of St Segment Elevation Myocardial Infarction for Hospitalized Libyan Non Diabetic Patients

coronary intervention. Circulation 124: 704711.

[26] Wahab, N., Cowden, E., Pearce, N., Gardner, M., Merry, H., Cox, J. et al. (2002) Is blood glucose an independent predictor of mortality in acute myocardial infarction in the thrombolytic era J Am Coll Cardiol 40: 17481754.
[27] Wiviott, S., Braunwald, E., Angiolillo. D., Meisel, S., Dalby, A., Verheugt, F. et al. (2008) Greater clinical benefit of more intensive oral antiplatelet therapy with prasugrel in patients with diabetes mellitus in the trial to assess improvement in therapeutic outcomes by optimizing platelet inhibition with prasugrel Thrombolysis in myocardial infarction 38 . Circulation 118: 1626 - 1636.

Citation: Hanan K. G. Altalhi, Asgad A. Abdalgbar. The role of HbAlc in severity and mortality rate of ST segment elevation myocardial infarction for hospitalized Libyan non diabetic patients. ARC Journal of Nutrition and Growth. 2019; 5(2):11-16. DOI: dx.doi.org/ 10.20431/2455-2550.050203.

Copyright: () 2019 Authors. This is an open-access article distributed under the terms of the Creative Commons Attribution License, which permits unrestricted use, distribution, and reproduction in any medium, provided the original author and source are credited. 